\title{
A COINCIDENCE THEOREM
}

\section{FOR THREE SYSTEMS OF TRANSFORMATIONS}

With a view to generalizing the Banach contraction principle, Matkowski [5]-[6] proved a fixed point theorem (see Remark 1) for a system of $n$ transformations, on a product of $n$ metric spaces. This result has been extended and generalized by Czerwik [1]-[2], Reddy-Subrahmanyam [7] and Singh-Kulshrestha [9].

We follow the notations of Matkowski [4] and Czerwik [2]:

$$
c_{i k}^{(0)}= \begin{cases}a_{i k} & \text { for } i \neq k, \quad i, k=1, \ldots, n, \\ 1-a_{i k} & \text { for } i=k,\end{cases}
$$

and $c_{i k}^{(t)}$ are defined recursively by

$$
c_{i k}^{(t+1)}=\left\{\begin{array}{l}
c_{11}^{(t)} c_{i+1, k+1}^{(t)}+c_{i+1,1}^{(t)} c_{1, k+1}^{(t)}, \\
c_{11}^{(t)} c_{i+1, k+1}^{(t)}-c_{i+1,1}^{(t)} c_{1, k+1}^{(t)}, \\
i, k=1, \ldots, n-t-1, \quad \text { for } \quad i=0,1, \ldots, n-2 .
\end{array}\right.
$$

The following lemma is essentially due to Matkowșki [5] (see also [2], [6] and [9]).

Lemma. Let $c_{i k}^{(0)}>0$ for $i, k-1, \ldots, n, n \geqslant 2$. The system of inequalities 
(3)

$$
\sum_{k=1}^{n} a_{i k} r_{k}<r_{i}, \quad i=1,2, \ldots, n,
$$

has a positive solution $r_{1}, r_{2}, \ldots, r_{n}$ if and only if the following inequalities hold:

$$
c_{i i}^{(t)}>0, \quad i=1,2, \ldots, n-1, t=0, \ldots, n-1 .
$$

Let $A_{1}, A_{2}, \ldots, A_{n}$ be arbitrary (nonempty) sets, $A_{:}=A_{1} \times A_{2} x_{0} \ldots x A_{n}$ and $x_{1}, X_{2}, \ldots, X_{n}$ metric spaces (with metrics $d_{i}$, respectively). Assume that

(5) $P_{i}, Q_{i}, T_{i}$ are transformations defined on the set $A$ with values in $X_{i}, \quad i=1,2, \ldots, n$;

(6) $\quad P_{i}(A) \cup Q_{i}(A) \subset T_{i}(A)$, and $\left(T_{i}(A), d_{i}\right)$ are complete subspaces of $x_{i}, i=1, \ldots, n$;

$$
\begin{aligned}
& d_{i}\left(P_{i}\left(x_{1}, \ldots, x_{n}\right), Q_{i}\left(y_{1}, \ldots, y_{n}\right)\right) \leqslant \\
& \leqslant \sum_{k=1}^{n} a_{i k} d_{k}\left(T_{k}\left(x_{1}, \ldots, x_{n}\right), T_{k}\left(y_{1}, \ldots, y_{n}\right)\right)+ \\
& +b\left[d_{i}\left(T_{i}\left(x_{1}, \ldots, x_{n}\right), P_{i}\left(x_{1}, \ldots, x_{n}\right)\right)+\right. \\
& \left.+d_{i}\left(T_{i}\left(y_{1}, \ldots, y_{n}\right), Q_{i}\left(y_{1}, \ldots, y_{n}\right)\right)\right]
\end{aligned}
$$

for all $\left(x_{1}, \ldots, x_{n}\right),\left(y_{1}, \ldots, y_{n}\right)$ in. $A$ and some nonnegative number $b$.

The following is the main result of this paper.

$T h$ eorem. If there exist nonnegative numbers $b$ and $a_{i k}$, $i, k=1,2, \ldots, n$ such that $(1)-(7)$, where

in which

$$
\begin{aligned}
& 0 \leq 2 b<1-\lambda, \\
& \lambda=\max _{i}\left(r_{i}^{-1} \sum_{k=1}^{n} a_{i k} r_{k}\right),
\end{aligned}
$$

then the system of equations 
(9)

$$
P_{i}\left(x_{1}, \ldots, x_{n}\right)=Q_{i}\left(x_{1}, \ldots, x_{n}\right)=T_{i}\left(x_{1}, \ldots, x_{n}\right)
$$

has a solution in $A$. Moreover, if

$$
P_{i}\left(v_{1}, \ldots, v_{n}\right)=Q_{i}\left(v_{1}, \ldots, v_{n}\right)=T_{i}\left(v_{1}, \ldots, v_{n}\right):=u_{i}
$$

and $P_{i}\left(\bar{v}_{1}, \ldots, \bar{v}_{n}\right)=Q_{i}\left(\bar{v}_{1}, \ldots, \bar{v}_{n}\right)=T_{i}\left(\vec{v}_{1}, \ldots, \bar{v}_{n}\right):=\vec{u}_{i}$

then $u_{i}=\overline{\mathbf{u}}_{\mathbf{i}}$.

Proof. First we note that, in view of the system of inequalities (3), $\lambda$ defined in (8) exists and $0<\lambda<1$ (cf. (Czerwik [2]). From the lemma and (8), we may choose positive numbers $r_{1}, r_{2}, \ldots, r_{n}$ such that

$$
\sum_{k=1}^{n} a_{i k} r_{k} \leqslant \lambda r_{i}, \quad i=1, \ldots, n .
$$

Pick $x_{i}^{0}$ in $A_{i}, i=1, \ldots, n$. Taking a clue from [8], we construct sequences $\left\{x_{i}^{m}\right\}$ in $A_{i}$ and $\left\{z_{i}^{m}\right\}$ in $T_{i}(A) \subset x_{i}, i=1, \ldots, n$ such that

$$
P_{i}\left(x_{1}^{2 m}, \ldots, x_{n}^{2 m}\right)=T_{i}\left(x_{1}^{2 m+1}, \ldots, x_{n}^{2 m+1}\right)=z_{i}^{2 m+1}
$$

and

$$
Q_{i}\left(x_{1}^{2 m+1}, \ldots, x_{n}^{2 m+1}\right)=T_{i}\left(x_{1}^{2 m+2}, \ldots, x_{n}^{2 m+2}\right)=z_{i}^{2 m+2}
$$

$m=0,1,2, \ldots$ We can do this since $P_{i}(A) \subset T_{i}(A)$ and $Q_{i}(A) \subset T_{i}(A)$.

We may assume that

$$
d_{i}\left(z_{i}^{0}, z_{i}^{1}\right) \leqslant r_{i}, \quad r_{i} \geqslant 1, i=1, \ldots, n .
$$

From (7)

$$
\begin{aligned}
d_{i}\left(z_{i}^{1}, z_{i}^{2}\right) & =d_{i}\left(P_{i}\left(x_{1}^{0}, \ldots, x_{n}^{0}\right), Q_{i}\left(x_{1}^{1}, \ldots, x_{n}^{1}\right)\right) \leqslant \\
& \leqslant \sum_{k=1}^{n} a_{i k} d_{k}\left(T_{k}\left(x_{1}^{0}, \ldots, x_{n}^{0}\right), T_{k}\left(x_{1}^{1}, \ldots, x_{n}^{1}\right)\right)+
\end{aligned}
$$


4

S.L. Singh, U.C. Gairola

$$
\begin{aligned}
& +b\left[d_{i}\left(T_{i}\left(x_{1}^{0}, \ldots, x_{n}^{0}\right), p_{i}\left(x_{1}^{0}, \ldots, x_{n}^{0}\right)\right)+\right. \\
& \left.+d_{i}\left(T_{i}\left(x_{1}^{1}, \ldots, x_{n}^{1}\right), Q_{i}\left(x_{1}^{1}, \ldots, x_{n}^{1}\right)\right)\right]= \\
& =\sum_{k=1}^{n} a_{i k} d_{k}\left(z_{k}^{0}, z_{k}^{1}\right)+b d_{i}\left(z_{i}^{0}, z_{i}^{1}\right)+b d_{i}\left(z_{i}^{1}, z_{i}^{2}\right) \leqslant \\
& \leqslant \sum_{k=1}^{n} a_{i k} r_{k}+b r_{i}+b d\left(z_{i}^{1}, z_{i}^{2}\right) .
\end{aligned}
$$

So

$$
d_{i}\left(z_{i}^{1}, z_{i}^{2}\right) \leqslant q r_{i}
$$

wherein $0<q=(\lambda+b) /(1-b)<1$. Similarly

$$
d_{i}\left(z_{i}^{2}, z_{i}^{3}\right) \leqslant q^{2} r_{i}
$$

Inductively

$$
d_{i}\left(z_{i}^{m}, z_{i}^{m+1}\right) \leqslant q^{m} r_{i}, \quad m=0,1,2, \ldots
$$

This implies that $\left\{z_{i}^{m}\right\}$ is a Cauchy sequence and has a limit in $T_{i}(A)$, $i=1, \ldots, n$. Call it $u_{i}, i=1, \ldots, n$.

Now let $\left(v_{1}, v_{2}, \ldots, v_{n}\right)$ be a point in $T_{i}^{-1} u_{i}$. Thus $T_{i}\left(v_{1}, \ldots, v_{n}\right)=$ $=u_{i}$. Then from (7),

$$
\begin{aligned}
& d_{i}\left(P_{i}\left(v_{1}, \ldots, x_{n}\right), Q_{i}\left(x_{1}^{2 m+1}, \ldots, x_{n}^{2 m+1}\right) \leqslant\right. \\
\leqslant & \sum_{k=1}^{n} a_{i k} d_{k}\left(u_{k}, z_{k}^{2 m+2}\right)+ \\
+ & b\left[d_{i}\left(u_{i}, P\left(v_{1}, \ldots, v_{n}\right)+d_{i}\left(z_{i}^{2 m+2}, z_{i}^{2 m+3}\right)\right] .\right.
\end{aligned}
$$

Letting $m \rightarrow \infty$ yields

$$
d_{i}\left(P_{i}\left(v_{1}, \ldots, v_{n}\right), u_{i}\right) \leqslant b d_{i}\left(u_{i}, P\left(v_{1}, \ldots, v_{n}\right),\right.
$$

that is $P_{i}\left(v_{1}, \ldots, v_{n}\right)=u_{i}, i=1, \ldots, n$.

$-326-$ 
Similarly $Q_{i}\left(v_{1}, \ldots, v_{n}\right)=u_{i}, i=1, \ldots, n$. This proved the existence of a solution of the system (9) in A.

To prove the last part of the theorem, let $\left(\overrightarrow{\mathrm{v}}_{1}, \overrightarrow{\mathrm{v}}_{2}, \ldots, \overline{\mathrm{v}}_{\mathrm{n}}\right)$ in A be another solution of the system of equations (9), that is $P_{i}\left(\bar{v}_{1}, \bar{v}_{2}, \ldots, \bar{v}_{n}\right)=Q_{i}\left(\bar{v}_{1}, \bar{v}_{2}, \ldots, \bar{v}_{n}\right)=T_{i}\left(\bar{v}_{1}, \bar{v}_{2}, \ldots, \bar{v}_{n}\right)=\bar{u}_{i}$, say.

Then, since we can assume $d_{i}\left(u_{i}, \vec{u}_{i}\right) \leqslant r_{i}, i=1, \ldots, n$, we have by $(7)$,

$$
\begin{aligned}
d_{i}\left(u_{i}, \bar{u}_{i}\right) & =d_{i}\left(P_{i}\left(v_{1}, \ldots, v_{n}\right), Q_{i}\left(\bar{v}_{1}, \ldots, \bar{v}_{n}\right)\right) \leqslant \\
& \leqslant \sum_{k=1}^{n} a_{i k} r_{k} \leqslant \lambda r_{i} .
\end{aligned}
$$

Inductively

$$
d_{i}\left(u_{i}, \bar{u}_{i}\right) \leqslant \lambda^{m} r_{i} .
$$

Letting $m \rightarrow \infty$ gives $u_{i}=\bar{u}_{i}$. This completes the proof of the theorem.

Remarks: 1. Matkowski's fixed point theorem [5] is obtained as a corollary from the above theorem when $b=0, A_{i}=X_{i}, P_{i}=Q_{i}$ and $T_{i}\left(x_{1}, x_{2}, \ldots, x_{n}\right)=x_{i}$ for each $x_{i}$ in $x_{i}, i=1, \ldots, n$.

2. Kominek's coincidence theorem [4, Th.1] generalizing the coincidence theorem of Goebel [3] and Matkowski's theorem is obtained from the above theorem when $b=0$ and $P_{i}=Q_{i}, i=1, \ldots, n$. Indeed, Kominek's theorem is proved using Matkowski's theorem while our approach is constructive and provides a method to construct a sequence converging to the coincidence value.

3. A fixed point theorem for two systems of transformations due to Singh-Kulshrestha [9] is obtained from our theorem when $A_{i}=X_{i}$ and $T_{i}\left(x_{1}, \ldots, x_{n}\right)=x_{i}$ for each $x_{i}$ in $x_{i}, i=1, \ldots, n$.

\section{REF ERENCES}

[1] S. Czerwik: Generalization of Edelstein's fixed point theorem, Demonstratio Math. 9 (1976), 281-285. 
[2] S. Czerwik: A fixed point theorem for a system of multivalued transformations, Proc. Amer. Math. Soc. 55 (1976), 136-139.

[3] K. Goebel: A coincidence theorem, Bull. Acad. Polon. Sci. Sér. Sci. Math. Astronom. Phys. 16 (1968), 733-735.

[4] Z. Kominek: A generalization of K. Goebel's and J. Matkowski's theorems, Uniw. Śląski w Katowicach, Prace Nauk.-Prace Mat. No. 12(1982), 30-33.

[5] J. Matkowski: Some inequalities and a generalization of $\mathrm{Ba}$ nach's principle, Bull. Acad. Polon. Sci. Ser. Sci. Math. Astronom. Phys. 21(1973), 323-324.

[6] J. Matkowski: Integrable solutions of functional equations, Dissertationes Math. Vol. 127 (Rozprawy), Warszawa, 1975.

[7] K.B. Reddy, P.V. Subrahmanyam: Extensions of Krasnoselskii's and Matkowski's fixed point theorems, Funcial. Ekv. 24(1981), 67-83.

[8] S.L. Singh: Some common fixed point theorems in L-spaces, Math. Sem. Notes Kobe Univ. 7(1979), 91-97.

[9] S.L. Singh, C. Kulshrestha: A common fixed point theorem for two systems of transformations, Pusan. Kyồ. Math. J. 2 (1986), $1-8$.

DEPARTMENT OF MATHEMATICS, GURUKUL KANGRI UNIVERSITY, HAR DWAR 249404 INDIA

Received July $13,1988$. 